\title{
De lo particular a lo general. La biografía y el contexto en el caso de Fulgencio Batista*
}

From the particular to the general. Biography and context in the case of Fulgencio Batista

\author{
ANDREA ALCÁNTARA JANEIRO \\ Universidade de Santiago de Compostela \\ https://orcid.org/0000-0002-6788-5507 \\ andrea17alcantara@gmail.com
}

\section{RESUMEN}

La consideración de la biografía como herramienta al servicio de la Historia ha variado sustancialmente desde el fin de los paradigmas historiográficos en la década de los ochenta del siglo XX. La renovación de la biografía conlleva un debate acerca de su naturaleza y sus límites, por el cual el género supera los arcaicos clichés decimonónicos que se le solían atribuir. En nuestro caso, a través de un estudio biográfico sobre el cubano Fulgencio Batista, pudimos comprobar cómo la biografía resultó ser el enfoque más propicio para, no solamente ilustrar las etapas de la vida pública y privada del personaje, sino también para retratar la época en la que este gobernó Cuba. Dando prioridad al contexto histórico que el personaje asimiló en sus primeros años de vida, y a las nociones que aprehendió de su entorno, entendimos al sujeto como resultado del tiempo histórico en que vivió.

Palabras clave: biografía, contexto, Fulgencio Batista, Cuba.

\section{Abstract}

The fact of considering biography as a tool at the service of History has varied substantially since the end of the historiographic paradigms in the decade of the 1980s. The renewal of biography involves a discussion about its nature and boundaries, by which this genre overcomes the oldfashioned nineteenth-century clichés usually conferred to it. In this case, by means of a biographical study about the Cuban Fulgencio Batista, we were able to verify how biography turned out to be the most suitable approach so as to, not only illustrate this character's public and private life periods, but also to depict the period in which he ruled Cuba. By giving priority to the historical context he assimilated in his first lifetime years, and to the ideas he apprehended in his environment, we understood this character as a result of the historical moment he lived in.

Keywords: biography, context, Fulgencio Batista, Cuba.

Este artículo es producto de la investigación recogida en Alcántara Janeiro, A. (2020): Fulgencio Batista (1901-1973): Cuba a través del personaje. Tesis doctoral del Departamento de Historia Contemporánea, Universidade de Santiago de Compostela, España. 


\section{INTRODUCCIÓN}

Valorar la biografía como recurso o enfoque a la hora de desarrollar una investigación histórica es una posibilidad más entre otras muchas. No obstante, hasta hace no mucho tiempo, la biografía y la Historia parecían formar parte de dos mundos diferentes y de imposible coexistencia. Las reservas que suscitaba el género, ya fueran estas motivadas por su particular idiosincrasia, sus limitaciones, o por su complicada evolución historiográfica, quedarían desterradas definitivamente con la irrupción de la crisis de los grandes paradigmas historiográficos en la década de 1980. La decadencia de las tendencias hasta entonces imperantes, las cuales privilegiaban los procesos de larga duración, las estructuras sociales y las colectividades -dando lugar a que el sujeto histórico del siglo XX fuese impersonal-, dio paso a la irrupción de otras nuevas surgidas en el cambio de siglo, al albor de la posmodernidad - las cuales abogaban por una franca subjetividad e individualismo-. La coyuntura derivada de este punto de inflexión historiográfico, unido a la caída de los sistemas comunistas y el auge del neoliberalismo (Peña Pérez, 2002: 49) dispuso un terreno perfecto para que el individuo y, por ende, la biografía, fructificasen.

Actualmente, son varios los debates sobre las posibilidades, límites y problemáticas de la biografía y su compatibilidad con la Historia. Una teorización en la que también hay lugar para entender la biografía como un ente con autonomía propia, al margen de cualquier otra disciplina. En este prolífico marco en el que se asienta la renovación biográfica, queremos destacar el salto adelante que supone entenderla desde un punto de vista multidisciplinar. La biografía entendida como enfoque en el desarrollo de una investigación historiográfica, en la que se combinan aportes de otras especialidades que analizan el comportamiento humano, como la Sociología o la Psicología, despliega un abanico lleno de nuevos horizontes en lo que a historia biográfica ${ }^{l}$ se refiere.

Atendiendo a esta multidisciplinaridad, planteamos nuestro caso haciendo valer teorías del ámbito sociológico y psicológico, referentes a cómo los individuos interpretan la realidad de los contextos sociales, históricos y culturales en los que se desarrolla su existencia. Esta base y una metodología propia del análisis de los procesos de liderazgo político utilizado en estudios propios de las Ciencias Políticas, nos permitió construir el retrato de la vida del cubano Fulgencio Batista -quien gobernó la Isla entre 1933 y 1958-. Sin embargo, este retrato no consiste en el manido relato que se ciñe al anticuado cliché de la narración de la vida y obras del personaje. Al estudiar al sujeto siguiendo este procedimiento no solo se logra una visión del mismo y las circunstancias que lo rodean a lo largo de su vida, sino que también se accede a una visión de lo que significó su tiempo. Nos referimos a aquella Cuba que iniciaba una nueva etapa poniendo fin a su pasado colonial en los primeros años del siglo XX, a la injerencia estadounidense en la joven república y a la continuidad de este proceso neocolonial siendo ya Batista la persona al frente del país.

1 Término acuñado por Sabina Loriga, por el cual se entiende la biografía aplicada a la Historia como: «aquella que se guía por una serie suficientemente formulada, pero también suficientemente flexible, de problemas históricos generales y que trata de explicar la singularidad de una vida individual sin someterla por ello a un relato que la trascienda o anule» (Burdiel y Foster, 2015: 11). 
Las particulares características que unen a Batista con el tiempo histórico que le toca vivir, así como su situación privilegiada en la Historia como personaje visible, lo convierten en un objetivo idóneo al que analizar usando la perspectiva propuesta. Entendiendo el estudio de su vida conforme a los parámetros planteados, a través del individuo podemos contemplar la progresión e inflexión de las estructuras coloniales y neocoloniales instaladas en Cuba desde los orígenes de la colonia española hasta la caída del propio Batista en la Nochevieja de 1958. Nacido a principios de siglo, con un padre soldado en la Guerra de Independencia, Batista, al igual que sus contemporáneos, interioriza desde sus primeros años la serie de realidades que conviven en la joven república cubana en un corto espacio de tiempo: la colonial y postcolonial española, los deseos de alcanzar una plena independencia, la mediatización estadounidense y el neocolonialismo posterior. Siendo así, partimos a la hora de iniciar un análisis biográfico sobre Batista de la íntima relación que parece adivinarse entre estos procesos históricos, la influencia de los mismos en la formación de esquemas mentales colectivos y las vidas de las personas que vivieron ese tiempo. En el caso que nos ocupa, qué duda cabe de que este bagaje adquirido en los años de aprendizaje, fruto del contexto en el que tiene lugar su existencia, influirá en el desarrollo de su persona y, por añadidura, en el modo en el que se desenvuelva en el poder.

A lo largo del presente artículo expondremos la metodología de nuestro estudio, pasando por el marco teórico en el que se basa, para terminar mostrando los resultados concretos aplicados al caso de Fulgencio Batista. Del mismo modo, resulta obligado realizar una mención a la situación de la biografía actualmente, la cual, sin duda, justifica la innovación metodológica que hoy proponemos.

\section{LA BIOGRAFÍA: EVOLUCIÓN Y SITUACIÓN ACTUAL}

Desde su aparición en el Mundo Antiguo, el cometido de la biografía era conservar para el recuerdo las hazañas de personajes memorables, y el método para conseguirlo era a través del relato de sus vidas. A esta finalidad se le añadió un nuevo componente en la Edad Media. A partir de entonces la biografía también sería un instrumento destinado a cumplir una misión moralizante y ejemplificante. No obstante, una característica de la biografía permaneció inalterable durante ambos periodos. En ella, realidad y componentes ficticios se entremezclaban por igual, siendo imposibles de distinguir. Este rasgo pasaría a ser entendido como una seña de identidad de la biografía, determinando su posición desfavorable en el plan historiográfico posteriormente. Juzgada como un género más cercano a la literatura, y en cualquier caso, impropio de una disciplina seria (Núñez García, 2013: 209), la biografía quedaría relegada a un lugar marginal en la historiografía del pasado siglo ${ }^{2}$.

2 El arrinconamiento historiográfico que sufrió la biografía fue menos acusado en ámbito anglosajón gracias a la arraigada tradición del género entre sus historiadores. 
La envoltura científica que adoptaron las ciencias sociales y humanas a finales del siglo XVIII (Loriga, 2015: 15, 16) es todo un anticipo del lugar que ocupará la biografía en este nuevo marco. El predominio del positivismo en el siglo XIX, así como el cambio de sujeto histórico de uno individual, hacia otro colectivo -el Estado y la Nación (Bermejo Barrera y Piedras Monroy, 1999: 234)-, constituyó un factor más hacia la exclusión que sufrirá en el siguiente siglo.

Con el ocaso del positivismo y la irrupción de la Escuela de Annales y el materialismo histórico, la historiografía del siglo XX se caracterizó por su interés en los procesos colectivos y supranacionales de larga y media duración, junto con el estudio de las estructuras y coyunturas sociales y económicas. Privilegiar estas temáticas conllevó rechazar otras, las cuales serían las asociadas tradicionalmente con la biografía: la historia política, la historia-relato y el acontecimiento. Sin apenas espacio dentro del marco historiográfico, la situación de la biografía no hizo sino empeorar en la década de 1970 con la irrupción de la Nouvelle Histoire, la Historia de las Mentalidades, la Historia Cuantitativa y la Historia Serial, cuyas metodologías cuantitativas retraían, más si cabe, al sujeto histórico individual, contribuyendo a una mayor despersonalización de la Historia.

Como ya hemos comentado, esta tendencia es revertida en la década de 1980 y actualmente podemos hablar de un fenómeno de restauración, renovación y/o retorno de la biografía. Una de las consecuencias de este regreso es la necesidad de esclarecer la multitud de dudas que parecen surgir en torno a un género que ha sufrido el abandono historiográfico como ningún otro. Es por ello que los debates sobre la biografía, su naturaleza, cómo desarrollarla, sus posibilidades, limitaciones y características son tan inevitables, como necesarios.

Entre los muchos temas controvertidos que encierra la biografía, destacamos especialmente las reflexiones relativas a los problemas y limitaciones que supone su uso en una investigación. Las problemáticas más recurrentes suelen ser las relativas a: la búsqueda de un consenso sobre el concepto de biografía ${ }^{3}$; la relación que se establece entre biógrafo y biografiado; la imposibilidad de conocer todos los detalles de una vida o las limitaciones del lenguaje a la hora de expresar las ideas oralmente y por escrito.

Por último, en lo que a renovación biográfica se refiere, es obligado destacar el fenómeno que en los últimos años está suponiendo la biografía «no escrita». Encontramos una variante del género biográfico en los biopics o películas biográficas, en los programas de tele-realidad en los que, tanto rostros conocidos, como desconocidos, exponen voluntariamente su día a día; en las plataformas y aplicaciones de internet destinadas a la exposición de las vidas de sus usuarios, o en las mismas autobiografías. Un fenómeno creciente que refleja una nueva forma de entender el género y su irrupción en la cultura popular y en los medios de comunicación. Curiosamente, en este proceso podemos observar como la

3 Destacamos dentro de este debate la propuesta sugerida por Paula Bruno, para la cual la biografía es entendida conforme a su función. Así existirían la biografía como género, como método o como recurso. Véase Bruno (2012) y Bruno, (2016). 
biografía vuelve a su finalidad primaria, la de preservar a los que eran dignos de ser recordados, esta vez en un contexto secularizado (Lee, 2009: 17, 18).

No obstante, de entre todas las innovaciones surgidas en el campo biográfico, destacamos para el caso que nos ocupa la posibilidad de aprovechar el conocimiento de otras disciplinas a la hora de enriquecer el estudio. A continuación, nuestra propuesta recoge cómo el uso de teorías ajenas a la Historia dotaron de coherencia a nuestro estudio biográfico, sin que su esencia eminentemente histórica se viese comprometida.

\section{LA RELACIÓN CONTEXTO-SUJETO COMO HILO CONDUCTOR DE LA BIOGRAFÍA}

Intentando sortear una de las problemáticas más habituales al emprender un estudio biográfico -que no es otra que la de caer en el error de construir un relato concatenado de fechas y sucesos que van aconteciendo progresivamente desde el nacimiento hasta la muerte del biografiado-, reflexionamos sobre el papel del sujeto dentro del espacio en el que su vida se desarrolla. Abandonar la idea de que la vida del individuo transcurre de forma independiente, para pasar a visualizarla como una pequeña parte dentro de un conjunto total, hace posible evitar ese error. El sujeto pertenece a ese «todo»y ahí tiene lugar su existencia, junto con otras personas y fenómenos. Es por ello que, invariablemente, debe valorarse al personaje como parte de un contexto activo del que recibe continuos estímulos, siendo influenciado e influenciando él a su vez. Es decir, en ningún caso puede ser separado el sujeto de su ambiente cuando analicemos su historia.

Desde nuestro punto de vista, el contexto debe ser considerado un actor principal en el desarrollo de situaciones: tanto como generador de las mismas, como por la influencia que ejerce sobre los agentes que participan de ellas. Sin olvidar, del mismo modo, su importancia en el desarrollo de trayectorias vitales y en la creación y conformación de esquemas colectivos. Atribuyéndole tales capacidades, pareciera que el contexto fuese un concepto demasiado amplio y abstracto. Es por ello que, en anteriores estudios (Alcántara Janeiro, 2020) planteamos una propuesta en la que delimitamos la noción de contexto, dividiéndolo según sus funciones respecto a su aplicación en el ámbito biográfico.

En primer lugar, entendemos el contexto en dos vertientes. Debemos distinguir, en primer término, el contexto como una estructura a un nivel macro que se impone sobre las colectividades, con capacidad de crear estructuras mentales y de comportamiento. Es decir, lo que conocemos como el contexto socio-histórico, cultural, etc., con facultad de crear «hijos de su tiempo». En segundo término, y a un nivel micro, entendemos el contexto como el entorno más próximo de los agentes, con el que estos interactúan diariamente (familia, grupo de allegados, instituciones en las que participan o a las que están subordinados -Estado, instituciones religiosas, educativas, etc. -) (Alcántara Janeiro, 2020: 35, 36). 
Partiendo desde un punto de vista constructivista ${ }^{4}$, la idea del contexto desde el macro-nivel es posible si consideramos que nuestra existencia y nuestro mundo son interpretados por las personas, resultando de esas interpretaciones esquemas mentales colectivos. Estas estructuras mentales producto de la interpretaciones de los contextos sociales e históricos serían el reflejo simbólico de las estructuras reales.

Cómo las personas construyen su realidad condicionados por su ambiente es un tema tratado en la sociología interpretativa ${ }^{5}$. Entre las teorías enunciadas a este respecto destacamos, por constituir la base de nuestra propuesta, la teoría denominada «del encuadre», también conocida framing o frame analysis, de Erving Goffman (1974).

Según Goffman, cualquier situación -lo cual incluye el ambiente en el que las personas se desarrollan- es susceptible de ser interpretada. Sobre esa interpretación, y en base a la experiencia, se crean modelos -a los que denomina marcos ${ }^{6}-$, que definirán situaciones similares futuras. Los marcos encuadran las situaciones y se construyen en función de lo vivido. «Cuando un individuo (...) reconoce un determinado acontecimiento, (...) tiende a involucrar (...) uno o más marcos de referencia o esquemas interpretativos de un tipo que podemos llamar primario» (Goffman, 2006: 23).

Siendo empleada esta teoría por su autor para describir procesos cotidianos relativos al comportamiento humano, actualmente el enmarcado es habitual en el estudio de los movimientos sociales y de la acción colectiva, en relación con los medios de comunicación (McAdam, McCarthy y Zald, 1990). No obstante, nuestro interés en el enmarcado radica en el modo de explicar la influencia que una macro-estructura ejerce en el inconsciente colectivo.

Enmarcar es un proceso colectivo, tanto en la fase inicial como después. (...) Parece natural que los procesos enmarcadores iniciales sean estratégicamente menos conscientes. De hecho, al principio, los participantes pueden no tener plena conciencia de estar tomando parte en un proceso interpretativo de importancia. (McAdam, McCarthy, y Zald, 1999: 40)

En un sentido similar, y también desde la sociología, «La Construcción Social de la Realidad» de Berger y Luckmann (1966) refleja un concepto similar. Los autores sostienen la existencia de una realidad objetiva y otra subjetiva. La realidad subjetiva sería fruto de una construcción del sujeto en base a la interpretación de la primera y de la intervención de terceros. A su vez, el individuo consideraría la realidad subjetiva como objetiva y real.

4 El constructivismo es una corriente que entiende las situaciones y la propia realidad como el resultado de su interpretación y definición social (Giner, Lamo de Espinosa y Torres, 2013: 163).

5 Rama reciente de la sociología centrada en el estudio de la interacción y los procesos intersubjetivos de definición de situación (Giner, Lamo de Espinosa y Torres, 2013: 867).

6 El uso del término marco (frame) por Goffman tiene su origen en el trabajo de Gregory Bateson (1955). 
Las definiciones que los otros significantes hacen de la situación del individuo le son presentadas a este como realidad objetiva. De este modo, él nace no solo dentro de una estructura social objetiva, sino también dentro de un mundo social objetivo. Los otros significantes, que mediatizan el mundo para él, lo modifican en el curso de esa mediatización (Berger y Luckmann, 2015: 164).

Como puede observarse, el elemento más reseñable de ambos planteamientos es la subjetividad. Al analizar cómo el contexto macro-estructural incide sobre los sujetos, realmente valoramos cómo el grupo y el individuo perciben su entorno, no la realidad del entorno en sí mismo. Una subjetividad que, coincidentemente, es parte fundamental también en la construcción de una biografía.

En segundo lugar, y dejando a un lado la construcción de realidades colectivas desde el macro nivel, otra función que atribuimos al contexto es la influencia constante que el ambiente ejerce en el desarrollo de cualquier sujeto -un fenómeno que, a diferencia del anterior, se produce en la micro-estructura-. Los ambientes más inmediatos, como los más exógenos, pueden determinar el pensamiento y acciones de un individuo. Desde las relaciones familiares (micro nivel), hasta las decisiones geopolíticas de gobiernos situados a mucha distancia en el espacio y en el tiempo (macro nivel), tienen la capacidad de condicionar el desarrollo y conducta de cualquier sujeto. Para ilustrarlo, al amparo de la psicología cultural ${ }^{7}$, queremos destacar una teoría que ilustra la faceta interventora del contexto sobre las personas: la «Teoría de la Ecología del Desarrollo Humano» de Urie Bronfenbrenner (1987). Nuestra atención recae en cómo son planteadas por el autor las relaciones sujeto-contexto y contexto-contexto, y la importancia que otorga al ambiente en el desarrollo vital. El autor al referirse al ambiente ecológico del individuo habla de una serie de sistemas: microsistema, mesosistema, exosistema y macrosistema, que se relacionan con el sujeto en función de su proximidad a este y, a su vez, entre sí.

Asumiendo, pues, la influencia directa del contexto «cotidiano» en nuestras vidas, consideramos ahondar en la manera en que es asumido, interiorizado y da forma a la personalidad de los individuos. Para ilustrar tal proceso -y considerando la propuesta de Jiménez Díaz (2009) en su análisis del proceso de liderazgo político del Presidente del Gobierno español, Felipe González-, el concepto de habitus acuñado por Pierre Bourdieu parece la opción más adecuada. Pues bien, ¿qué es el habitus? Para definirlo, que mejor que recurrir a la descripción que nos da el propio autor: «Las disposiciones de los agentes, sus habitus, es decir, las estructuras mentales a través de las cuales aprehenden el mundo social, son en lo esencial el producto de la interiorización de las estructuras del mundo social» (Bourdieu, 1988: 107).

$7 \quad$ La psicología cultural es un enfoque teórico-metodológico surgido a finales de los setenta, y consolidado a mediados de la década siguiente. Sus antecedentes pueden encontrarse en G.H. Mead y Lev Vygostki. Esta disciplina estudia cómo las tradiciones culturales y las prácticas sociales regulan, expresan, transforman y transmutan la psique humana (Sampson, s. f.: 1,3). 
Entendemos, pues, que el habitus es un vehículo mediante el cual las personas canalizan los estímulos del exterior, los interiorizan, y los hacen suyos. Cuando este proceso tiene lugar, al asimilar el sujeto las estructuras que le son familiares, y al comportarse conforme a un determinado entorno y ambiente, el habitus de cada individuo adquiere su forma.

Recapitulando lo expuesto, observamos como el sujeto se relaciona con el contexto desde dos niveles diferentes (macro y micro) a un mismo tiempo y que, en ningún caso, ambos niveles son excluyentes. De igual modo, queda patente como su impronta en el individuo, en todos los sentidos anteriormente comentados, es más que notoria y condiciona invariablemente el desarrollo y evolución de este. Es por ello que a la hora de plantear una propuesta de análisis biográfico, contexto e individuo nos parecen inseparables. De la misma manera, contemplando la vasta acción del contexto sobre la vida de un potencial biografiado, consideramos atajado el obstáculo que supondría construir un relato vacío en el que el personaje pareciese ajeno al mundo al que pertenece.

Involucrando desde el principio, e incluso antes de su propio nacimiento, al sujeto protagonista de la biografía con el ambiente en el que tendrá que desenvolverse no solo evitará que el personaje parezca descontextualizado a lo largo del relato, sino que ayudará a entender con mayor facilidad los porqués de sus decisiones, motivaciones y acciones. Al vincularlo de forma directa con su momento histórico, podremos acometer un análisis profundo del personaje en el que ese «todo» al que el biografiado pertenece adquirirá la importancia que le corresponde. No entendido como un escenario delante del cual actúan los actores, sino como una parte activa de la escena. El contexto analizado al mismo nivel que el propio biografiado responderá a muchos interrogantes sobre el personaje que, a priori, parecerían no tener explicación y, lo que es más importante, situará al sujeto dentro de su marco temporal, haciendo de él, ante todo, una persona de su tiempo.

\section{CONTEXTO, BIOGRAFÍA Y FULGENCIO BATISTA. OBJETIVOS Y METODOLOGÍA}

Enraizando al sujeto con el contexto, reflejamos en la biografía el pulso del tiempo en el que el personaje se desarrolla. Es decir, la biografía entendida desde este planteamiento nos permite ir de lo particular a lo general. Aplicando esta propuesta, el estudio de un caso individual no solamente tiene como resultado la obtención del retrato de la vida del biografiado, sino que también se obtiene de él una imagen del universo en el que se sitúa. De alguna manera, conseguimos así reflejar la generalidad de un tiempo partiendo desde un caso particular.

En el caso de Batista, antes siquiera de comenzar el análisis, lo primero que sopesamos fue el nivel de vinculación existente entre su figura y Cuba, dando por hecho que un estudio sobre su persona implicaba, invariablemente, que lo fuese también sobre la Cuba republicana. Llegar a esta conclusión fue sencillo atendiendo, en primer lugar, al nivel de 
perpetuación de su mandato en el tiempo -con una etapa pública que contempla dieciocho años en el poder a lo largo de tres décadas-. En segundo lugar, la capacidad de adaptación de la Cuba batistiana a los cambios impulsados por su mandatario en cada década según el contexto internacional imperante -podemos diferenciar claramente una corriente militarista en los años treinta, un salto democrático en los cuarenta, y un régimen autoritario decididamente anticomunista en los cincuenta-, nos induce a considerar a Batista el sujeto protagonista más representativo del periodo republicano, llegando incluso a identificarlo con el propio Estado. No obstante, y retomando la importancia de contextualizar al personaje y vincularlo a las circunstancias de su tiempo, reducir dicho estudio a los años de vida pública del personaje no parecía ni viable, ni ilustrativo, ya que, de ser así, estaríamos ignorando un factor clave que marcaría su vida, y la de sus contemporáneos: el colonialismo, la lucha por la Independencia y el neocolonialismo resultante de la misma.

Recapacitando sobre la perpetuación en el tiempo, la tendencia al cambio del régimen y la impronta del colonialismo y neocolonialismo en Cuba en la primera mitad del siglo XX; planteamos el estudio acercándonos al personaje desde dos perspectivas. Por un lado, contemplando la acción política y de control de Batista en su etapa pública. Es decir, analizando sus mandatos. Lo que podríamos considerar la vía de análisis más evidente para acercarnos a esa Cuba que queríamos retratar junto al personaje. Pero también, y buscando profundizar en la historia personal del sujeto, nos planteamos otro cauce de análisis: acercarnos a la idea de Cuba que el propio Batista pudiese haber adquirido mediante su experiencia vital. La cual habría condicionado, irremediablemente, su forma de desenvolverse en el poder en el futuro. Nuestra intención combinando ambas perspectivas era la de alcanzar a configurar el retrato completo del hombre, pero también el de la época que hizo suya.

Pero, ¿cómo plasmar la incidencia de las vicisitudes de la Cuba postcolonial en una biografía? Observando el modo en que Batista se desenvolvió en el poder, y la influencia que los Estados Unidos ejercen en Cuba durante sus años al frente del país, pudimos establecer una relación entre el peso del neocolonialismo de la Cuba batistiana y el que este mismo fenómeno pudo adquirir a principios de siglo en una localidad como Banes (Oriente), en la que Batista nacía y pasaba sus primeros años. Dicho esto, nuestro estudio pasaba, indudablemente, por identificar la incidencia del marco neocolonial colectivo aprehendido inconscientemente por los cubanos de principio de siglo en los usos y actuaciones de Batista en el poder.

Desarrollamos nuestro planteamiento partiendo de la base de que dicho marco es asumido por la sociedad cubana como una realidad tácita, por ser la única conocida hasta entonces y debido a la perpetuación de dicha macro-estructura a lo largo del tiempo. Dicho esto, indicamos que la asunción de la macro-estructura neocolonial como una estructura simbólica no quiere decir que se esté de acuerdo con esta o que no sea rechazada por el grueso de la sociedad. Simplemente significa que el arraigo de la estructura es tan profundo que la sociedad entiende su existencia como algo que es parte de su mundo. Deberá producirse una rotura completa del marco para que la sociedad descarte dicho esquema. 
Un momento que se producirá en 1959 con el triunfo de la Revolución. Cuando las reglas conocidas hasta entonces cambien, la macro-estructura neocolonial desaparecerá, al igual que el marco de referencia, siendo reemplazados por elementos distintos y nuevos.

Es en este punto donde el concepto de habitus puede sintetizar la injerencia del marco neocolonial en la persona de Batista. Como anteriormente comentamos, de la formación del habitus de un individuo se obtiene su personalidad. Este se conforma a partir de experiencias vitales, el entorno de los individuos, la asimilación de las estructuras, etc.; en definitiva, en base al ambiente que rodea al sujeto a lo largo de su vida. Es por ello que indagar en la formación del habitus de Batista en su infancia y juventud fue del todo pertinente para averiguar hasta qué punto las nociones asimiladas en ese tiempo pudieron condicionarlo haciéndose notar, posteriormente, cuando ostente el poder.

Siguiendo esta premisa, atendemos en primer lugar a una fecha: 1901, el año del nacimiento de Batista. En ese mismo año se redactaba la Constitución de la nueva república cubana, a la cual se anexaba como epígrafe la Enmienda Platt ${ }^{8}$. Una Cuba que, irónicamente, recorría sus primeros pasos como nación independiente tutelada por el estadounidense Gobernador Wood. La coincidencia temporal entre estos acontecimientos y el inicio de la vida de Batista ilustra con acierto lo determinante que será la injerencia del imperialismo estadounidense antes y durante los años del batistato.

Pero ese imperialismo de los primeros años, ese contexto neocolonial en el que se desarrolla Batista, no se manifestó solamente a nivel político. Las consecuencias de dicho contexto serán físicamente palpables en toda la geografía cubana. Banes, la localidad natal de Batista situada en la provincia de Oriente, fue una muestra más del influjo de las compañías norteamericanas en la zona con la presencia de la United Fruit y sus centrales azucareros. Asimilado el modelo productivo de Cuba con el monocultivo de azúcar exportador desde el último tercio del siglo XIX, y considerándolo como la principal fuente de riqueza del país, esta realidad tendría su continuidad durante los siguientes años y, desde luego, durante los batistatos. En cualquier caso, y desde la Independencia, los Estados Unidos serían el principal receptor y beneficiario de la producción azucarera cubana, contribuyendo al crecimiento del sector (Santamaría, 2006: 169).

Siguiendo la misma línea que parece enlazar la vida de Batista y sus decisiones futuras con el tiempo histórico que atraviesa la Cuba de principios de siglo, parece que el joven Batista era muy consciente de la actualidad cubana en sus primeros años. A juzgar por las múltiples referencias que podemos encontrar en los borradores de sus memorias y autobiografía inconclusa ${ }^{9}$, su padre, Belisario Batista, soldado en la Guerra de Independencia, parecía inculcar a sus hijos desde pronta edad las ideas por las que se había

8 La Enmienda Platt, sugerida en el Senado estadounidense por el senador Orville H. Platt, consistía en un anexo a la Ley de los Presupuestos del Ejército de los Estados Unidos. En ella se determinaban las bases de las futuras relaciones entre los Estados Unidos y Cuba. El documento sería incluido en la Constitución Cubana de 1901 a instancia de de los Estados Unidos.

9 Dichos borradores pueden consultarse en Cuban Heritage Colection (Coral Gables, Fl. EE. UU.), 5155 , serie III, cajas 98 y 99. 
combatido contra España. Es por ello que no albergamos duda de que las nociones aprendidas en esos años -todas ellas relativas a la situación del país y a la injerencia estadounidense en el mismo-, ya fuesen estas generadas a propósito del sentir popular, local o desde el mismo ambiente familiar, calaron profundamente en su imaginario. Por último, destacamos la firma de una serie de tratados leoninos entre ambos países, entre ellos Tratado de Reciprocidad Comercial (1903), y las intervenciones militares de los Estados Unidos en Cuba durante las dos primeras décadas del siglo XX, así como la amenaza de intervención militar cada vez que la seguridad de los intereses norteamericanos se veía comprometida, como otra constante en los primeros años de la Cuba independiente, que pudo ayudar al joven Batista a comprender el juego político de la Isla y por quién pasaba toda decisión que se acometía en el país.

Desde el mismo comienzo de su trayectoria política, será la embajada estadounidense quien mida los tiempos, posibilitando su ascenso y, posteriormente, su continuidad. Siendo consciente Batista del poder de influencia de los Estados Unidos en la Isla durante sus tres etapas de gobierno, entablará con el país vecino una relación de reciprocidad basada en la defensa de los intereses del país del Norte. Como contraprestación, estos preservarán su figura al frente de Cuba. No obstante, en el momento en el que Batista deje de ser una garantía para los intereses de los Estados Unidos, dicho país no tendrá reparos en romper esta relación, privándolo de su favor, para dejarlo caer, como sucederá en 1958.

Pero retomando el planteamiento de análisis que proponemos, decíamos que nos decantamos por dos vías de análisis encargadas de enmarcar al sujeto desde perspectivas distintas. La primera centrada en sus mandatos, la cual proporciona una visión directa de las acciones del personaje, mientras que la segunda aborda la parte más personal por focalizarse en el modo en el que Batista adquiere su habitus. A pesar de ser dos análisis diferenciados, no serían independientes, puesto que ambas vías consiguen converger desde los parámetros que S. Giner (1997) introduce desde «La Lógica Situacional»:

(...) Es menester reconocer la naturaleza bidimensional de toda lógica social: la de la acción intencional subjetiva, así como la de la dinámica propia de las estructuras en las que esta tiene lugar. Cuando decimos que toda acción está situada evocamos lapidariamente esta dualidad. Intención y estructura son inseparables. (Giner, 1997: 35)

Aplicando la idea de S. Giner encontramos un lugar en el que los espacios macro, la estructura neocolonial, y el micro-nivel -lo subjetivo; las acciones y habitus de Batistainteractúan, influenciándose entre sí. Siguiendo esta línea, en nuestro objetivo de acceder al personaje, pero también a una visión de la Cuba batistiana a través del mismo, denominamos «dimensión subjetiva» al análisis que parte desde el macro nivel hacia el micro nivel. A esta categoría pertenecen: 1) el marco de referencia neocolonial asumido por la sociedad cubana; y 2) la formación del habitus de Batista, donde se refleja la asimilación de dicho marco a nivel individual. A esta categoría corresponde el análisis de la infancia de Batista, de su entorno, de las relaciones y el pasado familiar. En definitiva, de todos 
los componentes que contribuyen a formar su personalidad, considerando siempre que los años de aprendizaje tendrán su impronta posteriormente durante los años en el poder.

En segundo lugar, contemplamos una segunda categoría de análisis a la que llamamos «dimensión objetiva», en la que prevalece la observación de las acciones de Batista, ya como personaje público visible. Esta consiste en atender a la naturaleza de los regímenes, los cambios y continuidades en los mismos, el modo en que Batista se desenvuelve, los apoyos, seguidores, detractores y la propaganda. En el caso de esta categoría, desde el nivel micro, la acción de Batista sobre Cuba, se alcanza el macro nivel, ya que, por su posición privilegiada, lo que Batista considere desde su puesto determina la estructura de todo el país.

Por último, y ceñidas a los supuestos de «la Lógica Situacional», queremos señalar cómo ambas categorías interaccionan entre sí. En el caso subjetivo, la estructura neocolonial aprehendida, es decir, el macro nivel, condiciona la forma en la que Batista se desarrolla en el poder en el futuro. Y en el caso objetivo, Batista desde el micro nivel -es decir, con sus acciones y su habitus - es quien de cambiar la macro-estructura, llegando a provocar con sus acciones, un movimiento contrario a su régimen, lo que acarreará el surgimiento de la Revolución. El triunfo de esta última, traerá consigo un cambio de marco de referencia, eliminando el neocolonial.

Los niveles de análisis escogidos ya mencionados: el marco de referencia neocolonial, el habitus, el ejercicio del poder y los seguidores y apoyos, beben directamente de los análisis de procesos de liderazgo político. Mediante la fórmula más básica de interpretar un proceso de liderazgo político: el análisis de líder-contexto-seguidores, propuesta por Jiménez Díaz (2013), adaptamos la misma a las necesidades de nuestro estudio. Bien es cierto que esta adaptación desde el plano de la politología al biográfico fue posible por tratarse Batista de una figura política. A su vez, nuestro interés en ilustrar los batistatos, por considerarlos un reflejo de la vida del personaje y dar las claves de la Cuba que buscábamos retratar, contribuyó en el fomento de un análisis biográfico vinculado a dicha disciplina.

Expuesta la propuesta metodológica, quedaría, no obstante, un obstáculo propio de la biografía por solventar. Este no se trata de otro que la cercanía o animadversión que el biografiado puede despertar en el biógrafo. Siendo uno de los problemas más comunes y complicados de solventar, en nuestro caso optamos por recurrir a la opción brindada por R. Gewarth (2015), quien en su trabajo sobre biografía y perpetradores del nazismo propone aplicar la empatía fría respecto al objeto de estudio. Tal proposición consistiría en apostar por una observación del personaje desde la perspectiva más profunda posible y comprenderlo lejos de meras simpatías o antipatías:

(...) con distancia crítica pero sin sucumbir a la tentación de confundir el papel del historiador con el de un fiscal en un juicio por crímenes de guerra. Puesto que los historiadores deben ocuparse principalmente de explicar y contextualizar, no de condenar, tienen que intentar huir de sensacionalismo y del tono enjuiciatorio. (Gewarth, 2015: 430) 
Una sugerencia, esta, con la que no podemos estar más de acuerdo, a pesar de la dificultad que implique, en ocasiones, abstraerse de las consecuencias de los actos del biografiado. Sin embargo, tomar esa distancia es necesaria si lo que se busca es que en la biografía quede patente el espíritu crítico con el que se inicia toda investigación.

\section{A MODO DE CONCLUSIÓN}

La recuperación de la biografía en general, y en el marco historiográfico en particular, ha supuesto una rehabilitación de un género marginado en el pasado siglo. Esta recuperación ha conllevado un consecuente debate sobre lo qué es biografía y lo qué como tal puede ofrecer. Dentro de este debate, optamos por destacar la posibilidad de aplicarla a la Historia en combinación con otras disciplinas, otorgándole un carácter multidisciplinar. El vacío que la biografía puede plantear por sí sola, parece desaparecer cuando se la enriquece con teorías procedentes de la Sociología, Psicología o Ciencias Políticas.

Nuestra propuesta concede la misma importancia a la vida del personaje, que al contexto en la que esta tiene lugar. Un estudio biográfico plantea, por su propia naturaleza, interrogantes que serán imposibles de responder aun con toda la información disponible a nuestro alcance -es imposible acceder al pensamiento de una persona, incluso cuando esta expresa su parecer abiertamente-, sin embargo, entendiendo el contexto como la otra cara de la moneda biográfica, podemos llegar a configurar una aproximación general, en la que muchas de las preguntas, a priori sin respuesta, puedan ser respondidas por si solas.

Ciñéndonos a nuestro caso, en primer lugar se decidió hacer un estudio biográfico sobre Batista, y en base a tal se desarrolló el método a seguir, sopesando las expectativas que buscábamos cumplir y las circunstancias del personaje. Teniendo en cuenta el proceso de elaboración del estudio, consideramos que el éxito a la hora de llevar a cabo un trabajo biográfico radica en adecuar el método que se vaya a aplicar a las variables del personaje a tratar. Con lo cual, llegamos a la conclusión de que lo más adecuado es dejar a un lado la búsqueda del método definitivo, aplicable sistemáticamente a cualquier sujeto y, en su lugar, valorar en primer término qué es lo que el personaje demanda, fijarse en sus necesidades, y en base a esto elaborar el método biográfico a seguir, adaptándolo como proceda.

Por supuesto, el análisis que planteamos adolece de un obstáculo y se trata de la personalización del mismo. Su acomodación a las particularidades del sujeto en cuestión es algo que, en teoría, le impediría convertirse en un método aplicable a gran escala a cualquier individuo -e incluso a cualquier otro «Gran Hombre»-. Descartando poder aplicarlo a un individuo anónimo, reconocemos que también sería particularmente complicado aplicarlo a un personaje conocido ajeno al mundo político. No obstante, realizando las pertinentes modificaciones al patrón propuesto, podría llegar a resultar funcional.

Sin embargo, al referimos a la relación contexto y sujeto concluimos que su aplicación es necesaria en cualquier estudio biográfico. Reconociendo el papel protagónico 
del contexto en el desarrollo de cualquier vida, dotamos de coherencia y respuestas a la investigación biográfica que nos propongamos. Algo que sucederá por igual tanto si el biografiado tiene repercusión histórica, como si no. Considerando al contexto como la piedra angular de cualquier biografía, lo que reste de investigación consistirá en empaparse del personaje. En el momento en el que el conocimiento sobre el mismo sea notorio, qué analizar y cómo hacerlo emergerá por sí solo, puesto que ya sabremos qué es lo que el personaje «pide» que se investigue de él. En cualquier caso, y tal y como apuntan Burdiel y Foster (2015: 10), interpretar y contextualizar deben de ser la base de la que partir en cualquier estudio biográfico. 


\section{BIBLIOGRAFÍA}

Alcántara Janeiro, A. (2020): Fulgencio Batista (1901-1973): Cuba a través del personaje. Tesis doctoral del Departamento de Historia Contemporánea, Universidade de Santiago de Compostela, España.

Berger, P. L. y Luckmann, T. (2015): La construcción social de la realidad. Amorrortu, Buenos Aires.

Bermejo Barrera, J. C. Y Piedras Monroy, P. A. (1999): Genealogía de la historia. Ediciones Akal, S.A., Madrid.

Bourdieu, P. (1988): "Espacio social y poder simbólico”, in M. Mizraji (trad.), Revista de Occidente, 81, feb., 97-119.

Bronfenbrenner, U. (1987): La ecología del desarrollo humano. Paidós, Barcelona.

Bruno, P. (2012): "Biografía e Historia, reflexiones y perspectivas". Anuario IEHS: Instituto de Estudios Histórico Sociales. 27, 113-119.

Bruno, P. (2016): "Biografía, historia biográfica, biografía-problema". Prismas, Red de Estudios Biográficos de América Latina, 20, 267-272.

Burdiel, I. y Foster, R. (2015): La historia biográfica en Europa. Nuevas perspectivas. Historia Global, Zaragoza.

Gewarth, R. (2015): "Empatía fría. Los estudios sobre los perpetradores y el reto de escribir la biografía de Reinhard Heydrich", in Burdiel, I. y Foster, R. (eds.), La historia biográfica en Europa. Nuevas perspectivas. Zaragoza, Historia Global.

Giner, S. (1997): "Intenciones humanas, estructuras sociales: para una lógica situacional”, in Cruz, M. (coord.), Acción humana. Barcelona, Ariel, S. A., 21-126.

Giner, S. Lamo de Espinosa, E. y Torres, C. (2013): Diccionario de Sociología. Alianza Editorial, Madrid.

Goffman, E. (2006): Frame Analysis. Los marcos de la experiencia. Centro de investigaciones sociológicas, Madrid.

Jiménez Díaz, J. F. (2009): "El liderazgo político de Felipe González en contexto”. Sociedad y Utopía: Revista de Ciencias Sociales, 33, 287-312.

Jiménez Díaz, J. F. (2013): "Los liderazgos de Adolfo Suárez y Felipe González en la Transición a la democracia en España (1976-1982)". Universidad de Macerata, Italia, 5-6 de noviembre.

En línea: [docenti.unimc.it/armando.francesconi/teaching/2015/14480/files/pdf-del-seminario-del-prof.-jose-francisco-jimenez].

Lee, H. (2009): Biography, a very short introduction. Oxford University Press, Nueva York.

Loriga, S. (2015): "La escritura biográfica y la escritura histórica en los siglos XIX y XX”, in Burdiel, I. y Foster, R. (eds.), La historia biográfica en Europa. Nuevas perspectivas. Zaragoza, Historia Global.

McAdam, D., McCarthy, J. D. y Zald, M. N. (1999): Movimientos sociales: perspectivas comparadas. Istmo, Madrid. 
Núñez García, V. M. (2013): "La biografía como género historiográfico desde la historia contemporánea española”. Erebea, Revista de Humanidades y Ciencias Sociales, 3, 203-226.

Peña Pérez, F. J. (2002): "El renacimiento de la biografía”. Edad Media, Revista de Historia, 5, 39-66.

Sampson, A. (s.f.): “¿Qué es la Psicología Cultural?». Universidad del Valle, 7.

En línea: [http://psicologiacultural.org/Pdfs/Materiales/Que\%20es\%20la\%20Psicologia\%20Cultural.pdf].

Santamaría García, A. (2006): "La economía de Cuba al final del régimen colonial y en el inicio de la república, 1861-1913", in Rodrigo y Alharilla, M. (ed.), Cuba. de colonia a república. Madrid, Editorial Biblioteca Nueva, S. L., 157-176. 